\title{
El inicio de la democracia en las fuerzas armadas españolas: los primeros militares rebeldes
}

\author{
Raquel Barrios Ramos
}

\section{RESUMEN}

Los preliminares de los rigurosos cambios que habrian de acontecer en el seno de las Fuerzas Armadas

españolas durante el período de transición a la democracia, corrieron a cargo de una parte bastante considerable de militares, los cuales, desde principios de la década de los setenta, emprendieron la difícil tarea de intentar encajar el colectivo al que pertenecian en el nuevo entramado político y social que se estaba configurando; liberándolo del peso de la dictadura con la que tantos años se les había identificado. Su actuación obedeció a la necesidad que, según ellos, experimentaba el Ejército de integrarse en el sistema democrático. Su actuación pretendió

sentar las bases para que esta Institución ocupase el lugar que le correspondía en la nueva sociedad que se estaba gestando.

Palabras clave: Edad Contemporánea, España, Transición democrática, Fuerzas Armadas, Unión Democrática Militar, Clandestinidad.

\section{ABSTRACT}

At the begin of the seventy years a part of spanish Armed Forces tried to introduce the democratic changes inside the military collectiv. They decided to free of franquism tradition and opening new expectatives for them; so they wanted to integrate the Army in the democracy in order to play a part in the new democratic society.

Key words: Modern Age, Spain, Democratic transition, Armed Forces, Military Democratic Union, Resistance. 
El esclarecimiento del proceso de adaptación de la dictadura a la democracia en España vino determinado por la conjunción de una serie de elementos que lo constituyeron: pluralismo político, reforma y ruptura, Constitución, Democracia y, sobre todo, consenso y conflicto. Estos últimos son dos términos tradicionalmente explicados en un contexto de transformación histórica. El consenso se da cuando hay una aceptación de leyes y normas; las instituciones deciden aplicarlas y la sociedad se identifica con las dos anteriores. $Y$ el conflicto, por su parte, se evidencia cuando surgen contradicciones y posturas encontradas; la complejidad social origina presiones de distintos tipos y se suscitan a su vez nuevos elementos desechando otros en el proceso de conversión que de forma irremediable causan tensión en la sociedad. Los cambios en la organización de la realidad social suponen la manifestación de distintos factores que tienden a crear un consenso o a radicalizar el conflicto. Todo ello canalizado por medio de las relaciones de poder.

El consenso en la transición española vino dado por el deseo de colaboración entre los diversos agentes participantes en la misma. Ello resultaba imprescindible para conseguir que la democracia saliese a flote y se alejase el fantasma de la inestabiiidad.

Sin embargo el conflicto estaba latente en nuestra sociedad desde mucho tiempo atrás. Las autoridades se encargaron de que el estado de cosas instaurado en 1939 no fuese de otro modo que el defendido por las jerarquias dominantes. Lo importante era hacer perdurar la evidencia que, ya desde el inicio de la guerra civil se había mantenido, de proclamar al conjunto del pueblo español la inexistencia de cualquier otra alternativa válida a la que era considerada como evidente, es decir, la del régimen de Franco.

El poder establecido se encargaba de que este estado de cosas no fuese de otro modo. Los verdaderos valores patrios sobre los que descansó la auténtica España desde ese Glorioso Alzamiento de 1936 fueron defendidos por quienes supieron interpretar su auténtica esencia -Estado e Iglesia-, y auspiciados por esos otros erigidos en el baluarte de nuestra nación: las Fuerzas Armadas.

« ¿Españoles! (...) -a nosotros- nos corresponden el paladinaje de una fe, una civilización y una cultura gravemente amenazadas por los principios rojos comunistas.

(...) Pocas personas en España se habían dado cuenta de los peligros que nos amenazaban. (...) mi consigna -la de Franco- fue la de uesperar atentos 
sin perder la fe en el Ejérciton. El Ejército ha salvado a España del caos y la ruina, demostrando a los enemigos del orden, a los escépticos y a los derrotistas que en el cuerpo que creían débil y minado continuaban perennes las tradiciones de lealtad y patriotismo. (...) El Gobierno rojo, desdichado, como azote infernal, ha dejado a su paso una estela de crimenes y sangre. (...) Esta conducta de enemigos de la unidad y de la grandeza de España no desaparece cuando la guerra acaba; al contrario, es su medio la paz, en que consideran su trabajo menos peligroso y más provechosas las ocasiones de debilidad y concupiescencia. Por ello tiene que ser mayor nuestra vigilancia y el cuidado de la pureza de nuestro credo" 1.

La omnipresencia de los militares durante el franquismo les impelía a especular con una percepción de la realidad española en la que su papel habría de ser decisivo. No podía ser de otra manera. Durante décadas se habian acostumbrado a llevar las riendas de la política y a partir de ahora podría contemplarse la posibilidad de que su capacidad de decisión se viese disminuida. Las Fuerzas Armadas habian sido el bastión del franquismo. Cumplian con la importante misión de servir de cantera política del régimen, representando su ideología, y desempeñar una labor represiva que preservase el orden establecido.

Teniendo esto en cuenta no resulta muy difícil entender que los militares no estuvieran dispuestos a ceder su parte de protagonismo en el sistema cuando éste estaba a punto de experimentar un cambio drástico. Por eso vivirán la evolución del proceso democrátíco totalmente condicionados. Y es por esto también que integrarian un potencial foco de conflicto que podría desequilibrar el normal progreso del discurrir democrático.

Sin embargo, no todo el colectivo militar entendía su papel en el futuro de la misma manera; principalmente desde los últimos años del régimen, en los cuales la sociedad española se imbuía cada vez más del ideal democrático. Así, las voces de aquellos militares que se declararon en contra de la legalidad establecida será cada vez más contundente. Entre la oficialidad, y también en la tropa, brotó la necesidad inminente de proclamar lo perentorio de una renovación decisiva de las Fuerzas Armadas; aunque sólo fuera para estar en óptimas condiciones de cara a un futuro en democracia, lo cual implicó la obligatoriedad de progresar hacia la implantación de la tan requerida libertad en el seno del Ejército salvando los escollos que se oponían a la misma, ya que «somos muchos los que en el Ejército nos sentimos identificados en lo fundamental, con estos compa-

1 Mensaje de Franco en el II Aniversario del Alzamiento. Burgos, 18 de julio de 1938; recogido en Palabras del Caudillo, ediciones FE, 1939 (págs. 135;140) 
ñeros. -Aquellos que son perseguidos por defender las ideas democráticas $^{2}$.

No obstante, y por todo lo dicho, se asoma una pregunta cuya formulación es irremediable, ¿qué argumentos esgrimían para desmarcarse de la comunidad a la que pertenecían, o sea la militar, e intentar rectificar su trayectoria?

Sus objeciones no se hicieron esperar. Lo importante era verificar su análisis en la observación del panorama que en esos momentos ofrecía el Ejército para que, partiendo de ésta, se meditase acerca de la conducta a seguir y así hacer desaparecer los factores que han ido condicionando su transformación, quedasen anuladas las influencias sufridas durante cuarenta años y se fijasen los pasos a seguir en favor de una integración en el proceso político de cambio: ${ }^{3}$

1. Triunfalismo. Es la actitud que durante cuarenta años han manifestado los vencedores de la guerra civil. Ello ha dejado una serie de secuelas que pueden resumirse en: espíritu de inmovilismo o inercia; olvido del sentido de la responsabilidad; concepción del mando militar como un virreinato ${ }^{4}$, especialmente entre los oficiales de más alta graduación, con tendencia clara al abuso de poder; mantenimiento de los cuadros profesionales dentro de la más profunda ignorancia, siendo esta faceta especialmente reforzada desde el Poder; deficiente nivel cultural de los mismos cuadros; y pérdida de prestigio entre la masa de la nación.

2. Los alféreces provisionales ${ }^{5}$. La incorporación de un ingente número de oficiales provenientes de la escala de alféreces provisionales es una de los inconvenientes más importantes que presenta el Ejército en

2 Carta abierta de "Nueva Lealtad" a todos los militares "Nueva Lealtad", 19-11-1975

3 Fuente; «Boletín de información para oficiales y suboficiales»; núm. de mayo, junio, julio y diciembre de 1971

4 Es importante aclarar que ésta y otras palabras o definiciones que aparecerán más adelante, tales como aborregamiento, espiritu borreguil, faginitis etc, no son más que una reproducción literal del vocabulario empleado por los militares que difunden sus ideas democráticas a través de las publicaciones clandestinas que se está procediendo a describir.

5 Cuando terminó la guerra civil en 1939 surgió un problema muy grave, por otro lado común a todas las guerras, que fue el del el exceso de personal. Aunque los oficiales profesionales procedentes de la Academia General Militar o de las academias especiales no eran demasiados, los aproximadamente $\mathbf{3 0 . 0 0 0}$ oficiales calificados como alféreces provisionales constituían un verdadero lastre. Se denominaron así a aquellos militares ingresados duranie la guerra que habían alcanzado el grado de oficial y suboficial, y a los que en principio no se les permite desmovilizar. Recordemos que, al objeto de aligerar el componente humano del Ejército, pronto comenzaron las desmovilizaciones, motivo por el cual en mayo de 1940 se licenciaron reemplazos de 1927, 1928 y 1929. 
esos momentos. La mayoría de estos hombres, sin vocación ni nivel cultural, encontraron en las Fuerzas Armadas el lugar donde asentarse de por vida; simplemente por el hecho de haber participado en la guerra.

Esta inflación de los cuadros de oficiales ha venido provocando problemas de diversa índole: Grave disminución de la ilusión profesional, puesto que capitanes y tenientes han de esperar una media de 10 ó 15 años para poder ascender debido al tapón que causa la presencia de los provisionales. Por lo que

«los oficiales jóvenes, que no tuvimos arte ni parte en la guerra civil, somos los que estamos pagando las consecuencias. Nos encontramos ante un Ejército técnicamente incapacitado para desarrollarse y cumplir su función esencial en un mundo superdesarrollado, políticamente mediatizado por un grupo de militares-políticos (Iniesta, Garcia Rebull etc) empeñados en que mantengamos un espíritu de guerra civil que los españoles, especialmente los jóvenes, (y los oficiales entre ellos) no queremos: nosotros no miramos hacia atrás sino hacia el futuro. Pero el Ejército no lo componen sólo esos generales, sino todas las clases y tropa y a nosotros nos corresponde cambiar lo que no nos gusta y frena nuestra carrera a la que tanto amor tenemos" 6 .

Adocenamiento y espíritu borreguil que expandió este grupo en el Ejército, puesto que siendo muy inferiores en cultura y preparación, en relación con sus superiores su actitud era sumisa y de sometimiento, y en relación con sus inferiores bastante despótica; Grave disminución de la coherencia interna del Ejército; Bajo nivel cultural del mismo; Pérdida de prestigio de cara al resto de la nación.

3. Un Ejército para el orden interno. Una de las notas más características de nuestro Ejército es su estructuración mirando exclusivamente hacia el interior del país, en función de las inclinaciones políticas del Jefe del Estado. Esto se pone de manifiesto a la hora de nombrar siempre ministros fieles a la causa, sin más preocupaciones, y al de eludir cualquier tipo de implicación que suponga la modernización de las Fuerzas Armadas.

Pero, como se acaba de decir, esta medida no afectó a los provisionales y el gobierno de Franco se vio obligado a promulgar una primera ley de reserva -17 de julio de 1973 - con el fin de conjugar el interés del Ejército, de la Hacienda y de los propios oficiales. Aunque tampoco solucionó el problema, al menos creó algunas condiciones ventajosas tales como cobrar prácticamente el sueldo integro, seguir conservando el derecho a la Seguridad Social del Ejército o continuar beneficiándose de los aumentos de sueldo.

Ante la insuficiencia de estas medidas en 1958 se promulgó una segunda ley que permitía a los oficiales que lo deseasen pasar a prestar sus servicios en ministerios civiles.

6 “Boletín de información para jefes y oficiales"; núm.2; mayo de 1970 (pág. 3) 
Las consecuencias inmediatas de esta excesiva politización del Ejército, de este mirar sólo hacia dentro, son dos: la ya mencionada pérdida de ilusión profesional y la supremacía de una autoridad virreinal por parte de los altos mandos.

4. Despolitización manipulada. La finalidad que el franquismo ha perseguido con esto es que el militar, sobre todo las altas jerarquías, sólo entiendan una única tendencia política: la establecida en el poder. Por eso su desinformación es absoluta; para que su obediencia sea igual de absoluta. De ahí que tantas y tantas veces se haya tenido que oir eso de que el militar es apolítico; que lo único que ha pretendido es crear fieles servidores en torno a Franco.

Las secuelas de esta despolitización forzada son también bastante evidentes: ignorancia política de los cuadros, y el mantenimiento de un espíritu feudal entre los altos mandos.

5. El escalafón. El militar está encasillado en su puesto. No presenta muchas opciones de mejora en su situación. El escalafón ofrece un carácter cerrado e inamovible debido al omnipresente nepotismo del Ejército. No se tienen en cuenta los méritos puesto que quien decide con demasiada frecuencia suele ser el "padrino" del aspirante. Todo lo cual se traduce en un arcaico sistema de ascenso.

6. La faginitis. La faginitis o faginosis ${ }^{7}$. El ascenso de coronel a general es por elección, no por antigüedad. Cuando cumpla la edad fijada, no pasará a la situación de retirado, sino a la de reserva, pero seguirá en activo, con lo cual podrá usar su uniforme siempre que lo desee. Además será socio, por propio honor, de cuantos Centros Culturales Militares o similares quiera sin necesidad de pagar ninguna cuota. Las consecuencias no pueden ser más notorias: total falta de responsabilidad, acomodación al puesto y una falta de esfuerzo imperante como nota caracteristica de esta escala.

7. El pluriempleo. La precaria situación económica de la mayoría de los oficiales impele a sacarse un sobresueldo; por lo que, fuera de las filas del Ejército, se verán obligados la inmensa mayoría de ellos a buscar otro oficio. Esto supone que, en vez de ser un militar comprometido, cada

7 Según se explica en uno de estos Boletines, uno de los vocablos más utilizados en el argot castrense de estos momentos es el de ufaginitis" o "faginosis", derivados de la palabra "fajín", símbolo de los generales, y con el que se quiere hace alusión en tono jocoso a la cómoda situación a la que ástos se ha acostumbrado a vivir, y a como se agarra al ufajin» para no deshacerse de los privilegios que éste el reporta. 
vez más irá a cubrir el expediente y se despreocupará por cumplir con sus labores castrenses. Esta situación no hace sino favorecer el inmovilismo y el desprestigio de las Fuerzas Armadas que, como Institución, no son capaces de ofrecer un futuro digno a sus miembros.

En conclusión, por un lado las Fuerzas Armadas no estaban preparadas para la vida moderna, entre otras cosas por su vieja y trasnochada legislación y porque arrastraban todos estos inconvenientes del franquismo. $Y$ por otro, y a consecuencia de lo anterior, no podían asumir adecuadamente su conversión a un auténtico Ejército democrático.

Resultaba prioritario relajar al militar de la carga de fanatismo que parece ser le habia sido propia durante todo este tiempo; sobre todo por parte de quienes vivieron la guerra, procurando que no se extendiese entre la oficialidad joven. Ello era necesario para dotar a la Institución del suficiente espíritu crítico que la convirtiera en un ente más capaz y más dotado. Con un mayor grado de cultura por parte del profesional que supusiera, a su vez, una mayor apertura hacia una mentalidad distinta de la existente en la mayoría de los militares por la cual fuese tomando conciencia de lo necesario de

«Defender la libertad para velar por un aprendizaje del ejercicio de la libertad, para ir bien desde las escuelas y en los cuarteles -y saber-qué es y qué representa la libertad personal y social, porque sabiendo entenderla sabremos defenderla, pero si se desconoce sólo se podrá defender la de los que la ejercen (...).

Defender la libertad para que no nos obliguen a escoger políticamente entre la clandestinidad y el Movimiento a pesar del contraste de pareceres.

Defender la libertad para luchar contra un Ejército anticuado, sin moral, sin armamento ni material adecuados, sin oficiales subalternos, ni apenas suboficiales, quienes con una escasa preparación técnica se ven obligados a improvisar continuamente e ir adecentando fachadas para que por lo menos se tenga un buen aspecto ante la revista de nuestros generales" 8 .

Pero era igualmente substancial cimentar toda esta casuística en una base sólida. Por eso en ella se encierran una serie de objetivos cuya consecución era imprescindible para que toda su doctrina adquiriera sentido: Creación de un Ejército democrático regido por una disciplina racional; Establecimiento de una élite dirigente que se preocupe continuamente de su perfeccionamiento para así servir mejor al pueblo, con

- "Boletín informativo para oficiales y suboficiales"; "Intereses mezquinos y bastardos" núm. mayo-junio, 1971 (pág. 7) 
la posibilidad de ser cambiados al menor síntoma de abandono de su gestión; Creación e impulso de un nuevo Ejército popular, esto es, para el pueblo, el cual se posicione siempre al lado del mismo; no en su contra; Desaparición del caciquismo y la inmoralidad en el seno del Ejército, evitando ser utilizado como ejecutor de las órdenes de una minoría o, en su defecto, de una potencia extranjera 9 ; Y, en último término, elaboración de una doctrina militar moderna ajustada a los nuevos aires democráticos que se avecinan frente a la doctrina fascista heredada, lo cual es indispensable para fundir las Fuerzas Armadas con el pueblo al que pertenecen, siendo ésta la mejor manera de convertir a los militares en un colectivo independiente.

Todo esto habría de alcanzarse para evitar perpetuar una situación de malestar, nacida de la escasa cuantía de los sueldos, mientras que el coste de la vida subía y obligaba a los militares más avispados a tener dos profesiones; de la deficiente dotación técnica; de la dependencia de nuestro Ejército de otras potencias extranjeras; y de la incapacidad de que se le dotó como colectivo para tomar sus propias decisiones. Amén del desánimo sobrevenido por el clima de corrupción vivido en la Administración y en muchos de los Altos Mandos, que recurrían al Ejército para remediar sus incompetencias utilizando sus uniformes para las tareas más impopulares. Su mala gestión se traducia, entre otras cosas, en acometer los gastos militares dentro del presupuesto nacional de manera equivocada. Era muy importante poner al día al Ejército y para ello hacía falta dinero. Sin embargo éste no se empleaba de la forma que se debiera. El porcentaje de los gastos militares con respecto al producto nacional bruto y la contribución por persona a la defensa era en España bastante inferior que la de muchos otros paises 10; además el hecho de que de-

9 Aquí se hace una clara alusión al tema de las bases norteamericanas y la OTAN, el cual constituye una preocupación constante entre estos militares

10 Los cifras que se manejan corresponden a los primeros años de la década de los setenta, y establecen que, en España, el tanto por ciento de los gastos militares en relación con el producto nacional bruto es de un $2,38 \%$ y la contribución por persona a la defensa, medida en dólares para poder equipararla con otros países, es de unos 18 dólares (entonces 1.200 pesetas aproximadamente). Esto sitúa a nuestro país en el puesto número 28 en cuanto al porcentaje del Producto Nacional Bruto dedicado a gastos de Defensa por debajo del resto de Europa, excepto Finlandia, Austria y Luxemburgo. Se observa una mayor diferencia en la inversión por persona de los países europeos (una media de 60 dólares) con la española, 17,64 dólares como se acaba de mencionar, convirtiéndose nuestro país en la nación europea que menos contribuye por persona a los gastos de defensa.

Por otro lado, en España el 73\% del presupuesto militar se destina a gastos de personal; $67 \%$ en Defensa Nacional y $91 \%$ en Seguridad Interior, dedicando las Fuerzas Armadas a la in- 
pendiésemos desde el punto de vista técnico y de armamento de otras potencias no hacía más que confirmar el carácter anticuado y el retraso de nuestro Ejército.

Sintetizando el asunto, lo que estos militares rebeldes denunciaron como los principales males que era necesario erradicar para acometer con éxito la transición fueron: la penuria que se evidenciaba en las Fuerzas Armadas españolas desde el punto de vista técnico y que hacía inminente su reequipamiento; La distribución del Ejército en función más de criterios políticos que de criterios estratégicos; Continuación de un compromiso político excesivo; Anquilosamiento de la cabeza visible del Ejército que sigue respondiendo a unos esquemas bastante rígidos; $\mathrm{Y}$, por último, desde el punto de vista humano, existencia de un Ejército considerado como uno de los más viejos del mundo.

Hasta aquí se ha seguido una evolución común en el tema. Quizás a partir de ahora resulte necesario bifurcar los caminos y establecer una diferenciación entre los integrantes de esos que se ha convenido en denominar militares comprometidos con la causa de la libertad.

En este sentido son dos las corrientes que se podrian identificar en el compuesto del Ejército. De un lado, aquellos que presentan nombre y apellidos. $Y$ de otro, los que no se dieron a conocer públicamente pero que actuaron en colectividad y con la mismas pretensiones que las de una organización perfectamente estructurada. Dentro del primer grupo se ha convenido en integrar a aquellos militares que consideraron oportuno sistematizar sus ideas liberales en torno a una formación determinada, esto es, la que pasó a conocerse como Unión Militar Democrática (UMD en adelante). En el segundo se encuadraron esa masa de militares que, sin atreverse a dar un paso tan contundente como los anteriores, se concienciaron de la problemática del Ejército al que pertenecían y adoptaron la misma actitud que ellos, difundiendo sus inquietudes políticas y sociales.

A principios de la década de los setenta un grupo de oficiales consideró que merecía la pena correr el riesgo, incluido el de enfrentarse al propio Cuerpo al que pertenecian y ser considerados una amenaza para la integridad del Ejército, y actuar a favor de la aceleración del proceso de-

versión real, esto es, armamento material e investigación únicamente unos 6.500 millones de pesetas. Todo lo cual evidencia la situación de desventaja de nuestro Ejército respecto de otras potencias europeas.

Fuente: «Boletines informativos para oficiales y suboficiales». Datos correspondientes a los primeros años de la década de los setenta. 
mocrático. Influidos por el denominado 25 de abril portugués ${ }^{11}$, en el que son precisamente los militares los que se erigen en avanzadilla del establecimiento de una democracia, estos oficiales se dieron cuenta de la necesidad de un conversión, considerando que "el cambio es necesario en una sociedad en cambio, a menos de quedarse atrás, aislados, trasnochados, formando un ghetto o apartheid respecto a la evolución social, humana, nacional e incluso internacional» 12.

Los acontecimientos de Portugal dieron la excusa pertinente a este grupo de oficiales para lanzarse a la aventura democrática. El comandante del Arma de Ingenieros destinado en Barcelona Julio Busquets fue el primer personaje que adquirió nombre propio en este asunto. Cuando se enteró de lo de Portugal consideró que había llegado el momento de actuar. Inmediatamente se puso en contacto con otros compañeros, los capitanes Julián Delgado, Juan Diego y Gabriel Cardona para comentar lo sucedido y reflexionar a partir de ello sobre la situación de las Fuerzas Armadas en España. Fue entonces cuando Busquets pensó que ya era hora de propagar la inquietud democrática en el seno del Ejército. Y es por eso que decidió seguir adelante y ponerse en contacto, también fuera de Barcelona, con todos aquellos militares que pensaran igual.

Era agosto de 1974. Busquets decidió dar forma a sus propósitos y convocó una reunión en Barcelona con todos los compañeros que él pensaba podrian ser aśines a la causa democrática. $Y$ para que esta diese

11 El 25 de abril de 1974 el Ejército portugués derribaba la dictadura que había tenido sometido al pais durante más de cuatro décadas. Este acontecimiento fue considerado todo un ejemplo para aquellos españoles, militares españoles, que deseaban el mismo destino para nuestro país.

El golpe de Portugal causó no poca intranquilidad en las esferas de poder franquista. Se intentó explicar lo sucedido justificando la movilización de las Fuerzas Armadas portuguesas simplemente por una reivindicación salarial. Para otros fue el resultado de un cambio social que no podia terminar de otra manera. Los que así pensaban sintieron que el Ejército portugués se había rebelado contra lo que era la opresión de una oligarquía dominante que obligaba a los militares a no servir realmente los intereses de su patria, sino los de esa minoría; idea que, precisamente, se pretendía fructificara entre los militares españoles.

Lo realmente preocupante para el gobierno de Franco fue la terrible influencia que estos hechos podrian ejercer sobre la oficialidad española. No era un buen ejemplo a seguir. Por eso aumentaron los servicios de vigilancia, se recomendó a los oficiales y suboficiales ser más severos con la tropa e, incluso, se autorizó a los mandos a desarrollar todas aquellas medidas intimidatorias que se considerasen necesarias.

No obstante todo ello no evitó que la tensión creciese en el seno del Ejército. La semilla, aunque fuese en tierra extranjera, estaba plantada.

12 Palabras pronunciadas por el general Luis Pinilla, citadas por CAPARRós, F.: La UMD: militares rebeldes Madrid, Argos Vergara, 1983 (pág. 24) 
sus frutos necesitaba contactar con Madrid. Del llamamiento hecho a la capital resolvieron acudir a la reunión los comandantes Luis Otero y Guillermo Reinlein y los capitanes Jesús Martín Consuegra, José Sagrado, Juan Diego, Enrique López Amor, José Julve, Gabriel Cardona, Antonio Miralles y Julián Delgado ${ }^{13}$. Todos ellos fundaron la UMD; primera, y única, agrupación militar comprometida en la consecución de la democracia en España.

En cualquier caso estos militares eran conscientes de lo arriesgado de su elección y de la dificultad de sacar adelante tamaña empresa. Hasta tal punto fue asi que fueron acusados de rebeldes, traidores y sediciosos porque ni a los altos mandos, ni al Gobierno, les gustó que existiese un grupo de oficiales que cuestionase el futuro de las Fuerzas Armadas. El Ejército era una pieza inamovible en el rompecabezas franquista que no podía sucumbir a ninguna presión. Habría de quedar claro para todos que "las Fuerzas Armadas son una Institución del Estado y como tal están por encima de toda política concreta, de toda opción cuestionable para, con su sola presencia y su potencia, si fuera preciso, garantizar la seguridad del propio Estado ${ }^{14}$.

Todo estaba perfectamente estructurado y programado. Las actividades de la UMD cada vez pasaban menos desapercibidas y la inquietud crecía entre la cúpula militar. El Gobierno, que ya sabía de su existencia, mantiene un estrecho cerco de vigilancia sobre ellos. De este modo, la preocupación por un brote revolucionario dentro del propio Ejército resultaba cada vez más alarmante. A todas luces aparecía como una organización clandestina con fines subversivos. Hasta tal punto era así considerada que en el verano del año 1975 los principales representantes de la organización fueron detenidos. La nota oficial que desde el Estado Mayor se dio sobre las detenciones concluía que la UMD era un movimiento clandestino en clara oposición con los principios fundamentales del Ejército al que atacaba directamente. Ello se justificaba por el hecho de que «su ideario y sus propósitos vulneran la unidad de las Fuerzas Armadas, la subordinación y la disciplina, esencia de sus virtudes castrenses, asi como las bases de actuación y misiones del Ejército que recogen las Leyes Fundamentales ${ }^{15}$.

13 Este último no estuvo presente debido a unas maniobras obligatorias que le ordenaron efectuar, aunque también se le consideró integrante de dicha reunión.

14 MINISTERIO DEL EJÉRCITO. ESTADO MAYOR CENTRAL. La "UMD" y la Causa 250/75 Talleres del Servicio Geográfico del Ejército, 1976 (pág. 11)

15 Nota informativa del Estado Mayor del Aire en relación con "La detención de varios oficiales", 4 de agosto de 1975 
Los altos mandos consideraron culpables a este atrevido grupo de militares. De este modo, fueron sometidos a juicio y el Fiscal Militar designado para la Causa 250/75, por la que serian juzgados, estableció que existía una organización subversiva dentro del Ejército. Explicó que entre sus objetivos figuraba el cambio ilegal de las Instituciones vigentes y, por ello, fue acusada por los delitos de "provocación a la rebelión militar» y "conspiración a la rebelión militar" (según los artículos 290 y 291 del Código de Justicia Militar). Todos los militares encausados serían condenados a cumplir penas de prisión.

Pero tras la muerte de Franco los cambios en la sociedad española se precipitaron hasta que, llegado 1977, las nuevas Cortes se plantearon la necesidad de promulgar una ley de amnistía efectiva que borrara definitivamente los efectos de la guerra civil y abriese claramente el camino hacia la transición democrática. Dicha ley ${ }^{16}$ aprobada el 14 de octubre de ese año amparaba a la UMD; es decir, contemplaba el perdón por la comisión de los delitos calificados de rebelión y sedición, por los cuales habían sido acusados y, por tanto, la aplicación de la amnistía les dejó en libertad; aunque no volvieron a reintegrarse en el Ejército.

En cuanto el afianzamiento de la democracia se convirtió cada vez más en una realidad palpable los miembros de la UMD decidieron disolverse; puesto que creyeron que al menos su objetivo principal, esto es, el establecimiento de la libertad en nuestro país, estaba cumplido.

Pese a todo, en el mismo seno del Ejército comenzaban a oirse voces distintas de las de los miembros y seguidores de la UMD que clamaban por una transición pacífica hacia un sistema democrático. Asi, un considerable número de oficiales y suboficiales empezó a distinguirse por su defensa de las ideas contrarias al franquismo, pero, como ellos mismos alegaban, sin perder de vista por ello el amor a la patria y el servicio a la

16 La Ley de Amnistía de 1977 perdonaba a todos aquellos que hubieran cometido actos con intencionalidad política antes del 15 de diciembre de 1976, cualquiera que fuese su resultado; todos los actos de la misma naturaleza cometidos entre el 15 de diciembre de 1976 y el 15 de junio de 1977 cuando "en la intencionalidad política se aprecie además un móvil de restablecimiento de las libertades públicas o de reivindicación de autonomias de los pueblos de España", y para el mismo tipo de actos contenidos hasta el 6 de octubre de 1977 siempre que «no hayan supuesto violencia grave contra la vida y la integridad de las personas". Los delitos comprendidos en esta ley son el de sedición y rebelión; objeción de conciencia; denegación del auxilio a la Justicia por la negativa a revelar hechos de naturaleza política; delitos o faltas cometidos por funcionarios, agentes y autoridades del orden público por la investigación y persecución de actos incluidos en esta ley; así cumo por delitos cometidos por funcionarios y agentes del orden público contra el ejercicio de los derechos de las personas. 
nación, condiciones que les definían como militares antes que cualquier otra cosa; entre otros motivos porque creian que no se podía tolerar por más tiempo la persecución de las ideas democráticas -defensa de la UMD- y que el colectivo militar no podía, ni debía, aguantar más una situación así; ya que tenían que ir creando los cauces que posibilitasen «(...) hacer efectivas sus aspiraciones, lo cual sólo será posible cuando el país goce de unas estructuras democráticas amplias. Y para lograr eso, sólo falta que nosotros, los militares, apoyemos activa y decididamente la salida democrática a la actual situación, que preconiza ese amplio abanico de fuerzas que engloba desde la derecha democrática hasta la izquierda» 17.

Al igual que hicieran los integrantes de la UMD, estos militares comenzaron la lucha por la libertad. Es más, hasta tal punto llegaron a identificarse con ellos, con su causa, que pensaron que con su organización había empezado verdaderamente el proceso de cambio en el Ejército de la España de esos momentos. Además, estaban convencidos de que la situación en nuestro país, en general, y en sus Fuerzas Armadas en particular no podía prolongarse por más tiempo.

«Pensamos que el paso de la dictadura a la democracia es inevitable. (...) El régimen se ha convertido en algo obsoleto, es el payaso de Europa. (...) La inevitabilidad del cambio es manifiesta. El problema y peligro de ese cambio estriba en que se produzca sin derramamiento de sangre, de forma civilizada y pacífica. Lo que pretendemos entonces es contribuir con nuestras informaciones claras sobre la situación real, a que dicho paso se efectúe de forma pacifica, a que ningún manejo golpista de la extrema derecha pueda convertir nuestro país en un baño de sangre. Lo que pretendemos también es que nuestra actitud democrática se conozca y extienda entre más amplios sectores militares, para que con la mayor colaboración activa de más elementos en el movimiento democrático, éste pueda ser llevado a efecto con más rapidez, y con mayor eficacia, evitando, repetimos, derramamientos inútiles de sangre. Pretendemos dejar de ser el elemento represivo de última instancia del país en su paso a la democracian 18.

Su prioridad, al igual que la UMD, será la de traer la libertad a nuestro país. Implantar un sistema en el que todos, sin excepción, y con independencia de su condición política o social, no tengan ningún miedo de expresar sus sentimientos ni hayan de ser perseguidos por ello. Ahora bien, estos oficiales quisieron dejar claro que no manifestaban ninguna preferencia política, ni se inclinaban por ninguna tendencia en concreto. Tan

17 “Carta abierta de Nueva Lealtad a todos los militares"; Nueva Lealtad, 19-11-1975

18 "Andalucia Miiitar", núm.1; diciembre de 1974 (pág. 2) 
solo proclamaban que estaban abiertos a toda la gama de intenciones ideológicas que tuvieran cabida en el espectro democrático; desde la derecha hasta la izquierda, pasando por todas las opciones que se puedan considerar. "Si decimos que no es misión del Ejército utilizar las armas para inmiscuirse en la vida política, ¿por qué hemos de entrar a juzgar cuestiones políticas? Los militares no queremos entrar en política, es que desde el poder se nos ha estado implicando siempre en ella ${ }^{19}$. "Nuestro estudio se realiza desde una óptica democrática, sin estar marcado por ninguna ideología política, pero abiertos a todas aquellas que respeten el derecho de las gentes a decidir sus destinos" 20 .

Pero todos estos militares con inquietudes revolucionarias necesitaban justificar su postura para dejar claro, no solamente que no hablaban en vano, sino que además su actuación y reacción, al igual que los militares de la UMD, tenía su razón de ser. Para ellos había que partir de una base muy sólida: primero la recapacitación sobre su situación y la necesidad de un cambio. Segundo, el inconformismo con la dictadura, puesto que es la causante de sus problemas.

Si las autoridades habían llegado tan lejos con un pequeño grupo de oficiales cuyo único delito fue el de reivindicar sus derechos y reclamar para sí y para el colectivo al que pertenecian la llegada de la democracia, ¿a qué está esperando el resto para despertar? Se necesitaban soluciones inmediatas y, según estos oficiales, estas pasaban por, en principio, desvanecer la triste realidad de sometimiento a un régimen caduco y anacrónico como el que vivian que les ha asustado, amedrentado e, incluso, menospreciado, durante tantos años. Después, utilizar la disciplina con su verdadero significado, esto es, fidelidad a los ideales de la patria y de defensa de los intereses del pueblo; y no como sinónimo de represión y sometimiento a la autoridad establecida; ya que "la ley y la disciplina están hechas para los que no piensan como los que están en el poder". Y por último, desvanecer la triste España de Franco, madurando y librándose de imposiciones que sólo les lleva a aceptar su falta de valor para preservar unos derechos que les corresponden, y de los que ahora no disfrutan, o para reaccionar ante tantas ofensas.

Ya no podian consentir que, cuando se alzan voces en su favor, éstas sean acalladas de la única forma que siempre se ha hecho, esto es, con el arresto; porque ya no pueden inhibirse de sus problemas y eximirse de

19 «Boletín informativo para oficiales y suboficiales", "Al lado del pueblo"; Madrid, diciembre, 1969; núm.1 (pág. 1)

20 «Boletín de oficiales y suboficiales», "Presentación»; julio, 1974; núm1 (pág. 2) 
los mismos como si no fuera con ellos. Porque «amamos el Ejército, todo esto tiene que repugnarnos, avergonzarnos, y servirnos de reflexión para saber hasta cuando hemos de permitir que nuestra Institución haya llegado hasta este punto de deterioro moral. Nuestros compañeros están detenidos por desear para el país la democracia y la libertad, por discutir sobre los problemas que a todo el Ejército preocupa, y por el deseo de que no seamos considerados como una casta de hombres distintos, aislados y dispuestos a oponerse a su pueblo ante el deseo de éste de reformar o cambiar la Constitución. (...)»21.

Sin embargo el verdadero sentido de las ideas que defendían estribaba en atraer a todos los militares a lo que consideraban más justo para ellos y para nuestro país, creando una expectativa de futuro legítima que supere la que en esos momentos se estaba viviendo. Ello no podía hacerse a la ligera; asi que tenian que difundir entre todos sus colegas lo que ellos creían que era la auténtica verdad de la España de esos momentos. El futuro de los militares como institución estaba en juego. No era lícito seguir pensando que el Ejército sólo es válido para salvaguardar el plan de vida instituida sin más. El seguir amparándola no suponía más que un atropello y una agresión hacia lo que verdaderamente han de representar. Nunca más el Ejército sería un policía, y nunca más se emplearía para debilitar la capacidad de defensa nacional. Especialmente cuando lo que desde hace tiempo se ha llamado el orden establecido, no es más que el desorden impuesto por la fuerza. Porque para el verdadero militar el único orden reconocido es el que está definido por la decisión popular, y es por tanto la defensa de la soberanía nacional a la que se debe consagrar la vida profesional de los militares; puesto que

"la vocación del militar es el patriotismo. Ni halagos, ni amenazas, ni prebendas, ni sanciones, pueden hacernos dimitir de esa vocación, y en legítima defensa se alza nuestra voz. Porque no aceptamos el Ejército sea instrumento para reducir al silencio a nuestro pueblo. Porque no confundimos la disciplina con una sumisión ciega. Porque para nosotros la Patria no es tanto una herencia del pasado como una proyección de futuro... Y ese futuro es un futuro democrático. Por todo ello afirmamos que si a los militares se nos obliga a tomar partido, si se nos obliga a definir nuestro puesto, nosotros nos definiremos sin vacilaciones, cueste lo que cueste. Ante los cambios urgentes que necesita España, nuestro lugar no está con quienes en último término sólo desean salvar sus beneficios, manteniendo situaciones injustas. Si llegada la hora de los cambios, de alcanzar aspiraciones legítimas de los grandes sectores que hoy se sienten oprimidos o

21 Escrito sin firma reconocida, dirigido $\propto A l$ resto de los compañeros»; fechado en enero de 1976 
postergados, se intentara desde el poder truncar su desarrollo pacíico obligándonos a definirnos a los militares, nosotros pensamos que el lugar de todo militar honesto está con el pueblo” 22.

Tenían que defender la compatibilidad entre el militar y el demócrata. Y para ello, no supieron, o no pudieron, dar con una fórmula más propicia que la divulgación de sus ideas desde la clandestinidad. Aunque, con la obvia excepción de los acontecimientos protagonizados por los miembros de la UMD, ésta fuese, más bien, una clandestinidad caracterizada por la letra y el discurso que por el activismo en su más estricto sentido.

El cuerpo fundamental de la propaganda clandestina de los militares de la UMD estaba compuesta por lo que podría intitularse la trilogía doctrinaria de la organización, consistente en tres documentos: el Ideario, el Manifiesto, y el denominado Estatuto del Militar, los cuales resultaban imprescindibles para comprender el verdadero mensaje de estos militares.

El Ideario surgió tras la famosa reunión de Barcelona, a partir de la cual, como ya se ha explicado, se puede hablar de la UMD como organización. Sus miembros justificaron su nacimiento por considerarlo un documento necesario para servir de pauta de comportamiento y empezar la reconciliación en España. Dicho Ideario,

«ha sido impuesto por las circunstancias de atraso, de aislamiento, de frustración, de falta de participación de las tareas del estado y de compenetración con nuestro pueblo que vivimos desde la terminación de nuestra guerra civil. -Este documento tan solo interesará- a todos aquellos que no se encuentren inmersos en los problemas de corrupción, de comodidad, de desinterés por los problemas del pais, de compromiso con los servicios de información del régimen o del Ejército, en una palabra, sólo llamará la atención de un profesional comprometido con la idea de conseguir pronto y de verdad la Patria y las Fuerzas Armadas que los españoles deseamos y los militares debemos ansiar. EI Ideario te muestra el camino para lograrlon 23.

De su contenido se destacan una serie de cuestiones principales: Obtener que las Fuerzas Armadas no se limiten a velar por los intereses del régimen, sino por los del pueblo español que es el único al que han de servir; Lograr que los miembros de la UMD estén dispuestos a cumplir con los objetivos nacionales y militares - de los cuales se hablará a continuación- planteados; Cumplir por un lado con la exigencia militar de lle-

22 "Boletín informativo para oficiales y suboficiales"; "Al lado del pueblo», Madrid, diciembre, 1969 (pág. 1)

23 Documento firmacto por la UMD, dirigido a todos sus compañeros, sin una denominación y título específico. Fechado en diciembre de 1975 
gar a ser oficiales ejemplares, y por otro, con la nacional de adquirir una profunda formación política. Y compromiso de no percepción de ninguna remuneración económica por su «actuación patriótica».

Esos objetivos nacionales y militares a los que se acaba de hacer alusión también se recogieron en el Ideario. Así, respecto de los primeros, lo que se pretendía era conseguir: el restablecimiento de las libertades en nuestro país, lo cual pasa por la concesión de la amnistía a todos aquellos, civiles y militares, castigados por defender ese derecho; la mejor distribución de la riqueza y reformas que a su vez mejoren las condiciones de los trabajadores, tales como el derecho a la huelga y a la sindicación; el derecho a elegir democráticamente a los representantes de los ciudadanos; y convocar una Asamblea constituyente, cuyos miembros hayan sido elegidos de forma democrática, la cual elabore una Constitución que responda a las necesidades de los españoles. Los objetivos militares por su parte, se centraban en: conseguir reorganizar las Fuerzas armadas creando un Ministerio de Defensa; dignificar a los suboficiales; revisar la Ley General del Servicio Militar con el fin de eliminar los privilegios que la misma encerraba; reformar el sistema de Justicia Militar restringiendo su ámbito de actuación a lo puramente castrense, así como la eliminación de instituciones obsoletas tales como los Tribunales de Honor; y elaborar un Estatuto del Militar - de lo cual, como ya se ha mencionado, hablaremos en breve- en el que se especifiquen sus deberes y derechos.

El Manifiesto, por su parte, fechado el 6 de enero de 1975, estaba dirigido, como en el mismo se indica, a "sus compañeros de armas" y tenía la finalidad expresa de convencerles de lo importante de percibir convenientemente las ideas, motivos y comportamiento de la UMD. En este documento se hablaba de lo ineludible de olvidar ese sistema que había dividido a España en dos, y del obligatorio cometido del Ejército de defender un nuevo orden basado en la justicia, la libertad, la igualdad y la paz. Ninguna de estas premisas podía alcanzarse bajo un régimen dictatorial. Este documento constituía una declaración en toda regla contra el mismo y una censura evidente de todo tipo de sociedad que reprime las libertades y oprime la expresión de los más elementales derechos:

«En España tenemos tan poca libertad como en Rusia (allí hay una dictadura de izquierdas y aqui de derechas) y en cambio no tenemos las ventajas de un sistema comunista en el que las clases sociales han sido abolidas ya que nadie puede poseer grandes bienes de producción (bancos, latifundios, grandes empresas) y por tanto nadie se beneficia del sudor del trabajo ajeno, con lo que alli ciertamente no hay libertad, pero al menos hay justicia social y ningún hombre es explotado por otro. 
(...) En el mundo occidental hay Libertad y Democracia Política pero no hay Justicia Social. En el comunismo hay Justicia Social pero no hay Libertad Política. En España no hay ni libertad, ni justicia. Ni hay partidos políticos, ni elecciones libres, oposición legal, sindicatos obreros etc.... como en Europa Occidental, ni se ha hecho la reforma agraria y la nacionalización de la Banca y de las grandes empresas como en Europa Oriental. Tenemos lo malo de todos y lo bueno de nadie» 24 .

En concreto este documento nos habla de un régimen político-liberal democrático. Hay que conseguir justicia y libertad; y para ello el Manifiesto propone dos vías: la evolución del actual sistema y la ruptura democrática. España evolucionará cuando se dé cuenta de lo importante que es el aperturismo. Para la UMD ésta era la única manera de estar a la altura del resto de los países de Europa occidental. El segundo camino, la ruptura democrática, se presenta como la única alternativa posible para el desarrollo del país. Todas las tendencias ideológicas convergerán en este punto. Es la única vía posible. Incluso plantean como inevitable la convocatoria de una huelga general y nacional como la mejor salida para dar paso a un gobierno de coalición que ellos definen como «el Gobierno de Salvación Nacional". Estos serian los pasos que habrían de darse para convocar una Asamblea Constituyente que diera lugar a la redacción de una nueva Constitución semejante a la del resto de los países de Europa occidental.

La elaboración del Estatuto del Militar completa esa trilogía documental que se ha señalado más arriba venía a puntualizar las líneas de pensamiento y actuación de la UMD. Este escrito, según sus autores, debería entenderse como el origen de una futura reglamentación de las Fuerzas Armadas. De dicho estatuto se desprendían tres ideas fundamentales: necesidad de crear un único ministerio de Defensa, lo innecesario de la existencia de los Tribunales de Honor, y una organización factible que admitiese todos sus postulados. En el primer artículo ya se dice que el Ejército ha de estar al servicio del pueblo. Su misión es la de estar velando por los intereses democráticos de la Patria.

Sin embargo, y puesto que se está exponiendo la propaganda ideológica difundida por estos militares, no sería correcto finalizar la misma si no se dedicasen, aunque sólo fuesen unas líneas, a exponer las ideas contenidas en otro de los escritos que resulta imprescindible conocer para saber exactamente por dónde se conducían los integrantes de la UMD. Así, el ti-

24 Manifiesto de la Unión Democrática Militar, «El actua! régimen político español» 6 de enero de 1975 
tulado “¿Dónde están los Capitanes?», firmado por el capitán José Julve, uno de los más directos implicados, pretendia llamar la atención sobre lo que debería ser, y en su opinión no es, el Ejército. Es un documento más que redunda en la tan reiterada idea de lo urgente de un cambio; o de una ruptura democrática, según se prefiera. Aquí se evidenciaba cómo es perfectamente comprensible que el pueblo español en general rechace a los militares puesto que, a sus ojos, éstos aparecen aislados, aburguesados y sin muchos ánimos para cambiar la situación. Sin embargo, se hace hincapié en el hecho de que no todos los militares son iguales; no son un bloque homogéneo. Solamente hay que tener en cuenta que durante muchos años los militares han recibido una educación muy represiva, y que se les ha acostumbrado a identificarse con una tendencia política sin más discusión. Sus intereses han tenido que coincidir por fuerza con los de Franco; y eso debe terminar. Las Fuerzas Armadas representan una institución muy definida y su papel ha de estar muy claro.

«La Unión Militar Democrática (UMD), es consciente, nace de entre los oficiales que ten 4 mos como único objetivo el que las Fuerzas Armadas dejen de ser la guardia pretoriana de una oligarquía que viene oprimiendo a nuestra nación desde hace treinta y cinco años. No queremos ser protagonistas de un episodio que divida nuevamente a España. Pretendemos acabar con los odios que aún perduran, y aislar a los que, con reiteración, se vienen encargando de recordarnos que hubo unos vencidos. (...) Los enemigos no son ni las orquestaciones del exterior, ni el comunismo, ni la masonería, sino que es el pueblo el que pugna, en su impotencia, mientras las Fuerzas Armadas siguen al lado de las clases dominantes, por deshacerse del yugo por el que un día fue uncido por unos Generales ambiciosos que no quisieron reintegrar al poder a aquel pueblo al que pertenecian.

(...) Nos mintieron cuando nos presentaron a la Patria como una idea. La Patria no es una idea, sino algo concreto del que somos. La Patria es el pueblo (...). Recordemos también que han tratado de imbuirnos la idea de que el poder político procede de Dios, para así justificar el que le habían arrebatado al pueblo. Nosotros sabemos que este poder lo deben ostentar los gobernantes con el consenso popular, mas no por la "Gracia de Dios".

Los militares somos conscientes de que nuestro papel no está en el protagonismo político tras la ruptura. Se reduce a favorecer ésta en colaboración con la gran mayoría del Cuerpo social del país, y tras ella dar paso a los partidos, que es lo mismo que decir al pueblo, para que sea él quien decida por medio del Gobierno que lo represente, la nueva andadura de una España por el camino de la libertad» 25. 
Pero en lo que respecta al resto de los militares que, sin ser miembros explícitos de la UMD, se unieron a ellos a favor de la causa de la libertad, encontraron otra forma igual, aunque más anónima, pero no por ello menos contundente, de alzar sus voces contra la dictadura. Estos oficiales, siendo conscientes de su problemática, y al no poder expresarse libremente, decidieron adoptar la misma actitud que cualquier otra fuerza política contraria al régimen de Franco y, por tanto prohibi$\mathrm{da}$, difundiendo sus inquietudes políticas y sociales a través, como se viene repitiendo, de la única arma que les dejaron: la propaganda clandestina.

Desde el principio de su existencia los oficiales complicados en la misma argumentaron que actuaban así porque no les quedó más remedio. Habían sido constreñidos a acallar sus opiniones, sentimientos y necesidades; y eso, no sólo no podía silenciarse, sino que, además, resultaba indefectible proclamarlo al resto de los compañeros. A pesar de que

«nos gustaría mucho poder hablar contigo -militar- de viva voz y a la luz todo lo.que debemos decirte desde estas hojas. Pero hoy se nos niega la voz, el derecho a hablar que otros entienden poseer en exclusiva; la información y opinión sancionada por una legalidad que estimamos ilegítima va en un determinado sentido que no es el nuestro. Por eso nos vemos obligados a actuar de una manera que no nos gusta, pero que es la única forma de hablar que tenemos» 26.

Pero sobre todo lo que también querían dejar claro es que no presentaban ninguna filiación política. Es decir, a pesar de que estaban abiertos a toda la gama de tendencias ideológicas que se pueden contemplar en un sistema democrático, quisieron evidenciar que con su postura lo único que quisieron fue estudiar la realidad desde la óptica de la libertad, sin inmiscuirse estrictamente en asuntos de política. No era su misión entrar en ella; sino contribuir a su transformación.

Dejaban así justificada su clandestinidad, aunque no les haya quedado más remedio; pese a que «como militares, como ciudadanos y como españoles nos repugna que el procedimiento tenga que ser la clandestinidad, el anonimato que puede parecer cobarde. La realidad de los hechos nos obliga a actuar así. Ello no es culpa nuestra, sino de aquellos

26 «Nueva Lealtad", núm 1, julio de 1974; (págs. 1/2).

Ésta es una publicación en torno a la cual se aglutinan oficiales y suboficiales con inquietudes democráticas, y cuya existencia justifican explicando que "son un grupo de militares de ideas democráticas que, imbuidos por el amor a la patria y el servicio a la nación, necesitan hacer llegar -al resto de sus compañeros- sus ideas y reflexiones sobre su país y su Ejércitox. 
que nos empujan a actuar así» 27. Por tanto, se consideraban unas víctimas más del gobierno que tenía nuestro país.

El primer hecho que evidenciaron, como muestra de en lo que se estaba convirtiendo el Ejército, fueron los acontecimientos relacionados con los componentes de la ya explicada UMD. Al ser los primeros que dieron la cara por las Fuerzas Armadas, existía la obligación moral de defenderlos; puesto que, de este modo, se defendía al mismo tiempo el noble ideal de la libertad.

El conformismo no podia tener cabida en una situación como la que se estaba viviendo. Por ello el primer paso que habría de darse era, precisamente, el de la recapacitación. Si las autoridades habían llegado tan lejos con un pequeño grupo de oficiales cuyo único delito habia sido reclamar sus derechos para sí y para el colectivo al que pertenecían, ¿a qué estaba esperando el resto para despertar? Habia que buscar soluciones, las cuales pasaban por dejar de someterse a un sistema caduco y anacrónico; utilizar la disciplina en su verdadero significado, esto es, fidelidad a los intereses de la patria y del pueblo; $y$, en último término, dar testimonio con tranquilidad de sus opiniones.

No obstante estos militares quieren servir, no solamente de centro de denuncia y quejas, sino que consideran igual estimable el convertirse en foro desde el que se divulgue la verdadera opinión de los que responden a la auténtica idea de lo que debe ser un militar. Especialmente teniendo en cuenta que el futuro de los militares como institución estaba en juego; al menos eso creían los que estaban comprometidos con la causa de la libertad. Porque el Ejército, como ya se ha dicho, no ha de ser nunca más un policía, y porque nunca más ha de ser empleado para debilitar la capacidad de defensa nacional.

El movimiento por la libertad dentro de las Fuerzas Armadas, no solamente abarcó a esa parte de la oficialidad comprometida con la causa democrática, sino que, además, en el grueso de la tropa hubo muchos soldados que, en estos momentos de la vida española, también se preguntaba qué función desempeñaban dentro de las Fuerzas Armadas; cuál era realmente el auténtico sentido quie se les confería.

Muchos de los jóvenes que pasaban a engrosar las filas del Ejército consideraban que tan solo servirian de fuerza de choque y punta de lanza ante invasiones extranjeras. Estar, como suele decirse, en primera lí-

27 «Andalucra Militam, «Presentación»; diciembre, 1974; núm.1 (pág. 2) 
nea, sirviendo, una vez más, a los intereses de una minoría dominante. Sentian que en la práctica el gobierno sólo se preocupaba de «(...) procurarnos un adoctrinamiento ideológico, en teóricas y conferencias, -muy conducido - tratando de enfrentar al Ejército con el pueblo. También se producen constantes bulos (asaltos a los cuarteles, robos de armas, voladuras de polvorines...) en momentos críticos, para provocar nuestra intervención. -Somos víctimas- de la utilización, bien por el terror o por la represión directa del Ejército contra el pueblo" 28.

Así las cosas, los soldados, o al menos algunos de ellos, empezaron a efectuar un llamamiento al resto de los soldados y a los mandos honrados para concienciar a unos y otros de la problemática de la situación.

Llamaron a sus compañeros a luchar contra la explotación económica a que eran sometidos en los cuarteles (comida, cantina, transportes, chapuzas a mandos, sanidad etc); a combatir los malos tratos y la disciplina fascista; contra la represión en el seno de las Fuerzas Armadas; a denunciar al régimen por su utilización fraudulenta del Ejército; a oponerse a utilizar las armas contra los propios compañeros, obreros, campesinos, estudiantes etc; a reivindicar un salario durante el Servicio Militar; a romper el aislamiento del cuartel, relacionándose con el pueblo; y a llevar a los cuarteles las luchas populares.

Son todos ellos motivos más que suficientes para que proclamen: ¿SOLDADO: organizate y lucha colectivamente por estos objetivos!!

No entendian por qué no están en los cuarteles para servir a la Patria ni para hacer un servicio de defensa militar del territorio, sino que, por el contrario están siendo preparados ideológica y físicamente para intervenir en la calle.

"-Cuando la élite dirigente se asusta y ve peligrar sus intereses- se nos acuartela en situación de "alerta" en los cuarteles más importantes, aumentan considerablemente los retenes y se nos distribuyen armas. Se nos anulan los permisos, se nos retiran los «pernoctas", aumentan las guardias y, en general, se endurece la histérica disciplina fascista. Todo está preparado para la intervención inmediata en la calle.

(...) A la política de los Campano, Iniesta, y demás ultras, claramente apoyada desde fuera de las Fuerzas Armadas por los sectores más fascistas, y claramente tendente a imponer la más férrea dictadura militar, hay que oponer la más firme lucha por un gobierno democrático, por la libertad, por

28 "La voz del soldado"; «Al pueblo de Madrid»; núm.4, septiembre, 1973 (pág. 2) 
un control del Ejército por las fuerzas populares y democráticas que están en su seno» 29.

Pero, como no podía ser de otro modo, a la tropa también le preocupaba otro tema que les afectaba muy directamente: el Servicio Militar, y también se ocuparán de ello.

Lo primero que denunciaron fue lo triste que resultaba que para la mayoría de los altos mandos el soldado no era sólo un defensor de la Patria. Se quejaban de que tras los discursos y las banderas trataban de ocultarles que, al jurar, lo que les estaban obligando a hacer era comprometerse a defender el régimen, es decir, a servir de instrumento represivo contra el pueblo. Y a eso es a lo que se reduce fundamentalmente el Servicio Militar. En vez de ser una escuela en la que aprendan a ser capaces de defender la independencia de España, lo único que parece es una academia de policía donde imparten un curso denominado «mili», que no vale más que para revolverse contra el pueblo cuando un grupo de oligarcas así lo decida.

En lugar de considerarlo como un período de formación provechosa, a raíz del cual el joven sienta más profundamente su amor por la Institución a la que pertenece, aunque sea de forma temporal, éste se convierte en "un mal trago que hay que pasar» lleno de calamidades e injusticias, tales como malos tratos, arrestos arbitrarios, comida escasa, precios abusivos en las cantinas y su utilización forzosa como mano de obra gratuita. En definitiva el Servicio Militar se reduce a una relación entre explotadores y explotados que, además, se prolonga innecesariamente en el tiempo.

Su duración sería el segundo inconveniente. Es un contrasentido estar meses y meses perdiendo el tiempo cuando podria, y debería, emplearse en asuntos mucho más productivos. No es de extrañar que muchos jóvenes vean su paso por las Fuerzas Armadas como un prolongado paréntesis con el que lo único que van a conseguir es sentirse defraudados, utilizados y desperdiciados. Es inútil pedir a los mandos una reducción del tiempo de duración del Servicio Militar, ya que ellos argumentan que las nuevas técnicas militares, su aprendizaje, y los cambios estratégicos que se están viviendo exigen una dedicación completa. Para el soldado esto es un craso error teniendo en cuenta que están marginados de los avances técnicos importantes y complejos, y los métodos de instrucción y de enseñanza no se adecúan a las actuales exigencias. Por eso podria dis- 
minuir la duración de la mili sin perjudicar a la formación de la tropa, porque, además, gran parte de su tiempo lo pasa en servicios de mantenimiento y conservación de los cuarteles (guardias, cocinas, limpiezas...), y desocupado en permisos, destinos burocráticos y serviles, con lo cual desaprovecha totalmente lo que habría de totalizar la verdadera formación de un soldado.

Los que así pensaban, creían que la labor de promoción social, tanto cultural como profesional, de la tropa era prácticamente inexistente. Era sólo una cortina de humo, mal planteada, mal dirigida y mal realizada. Censuraban que sólo sirviese para falsear las cifras oficiales de analfabetos en el país, para justificar unos monstruosos gastos ficticios, para aumentar el número de puestos burocráticos en el Ejército, pero nunca para justificar su prolongación en el tiempo.

En definitiva, la razón de que su estancia en el Ejército esté planteada de esta manera, según los propios soldados, no era otra que política. Al régimen le interesa su conservación tal y como está porque su permanencia incorporados a filas supondría mantener un contingente de hombres casi constante dispuestos, obligados, a empuñar las armas cuando los medios represivos civiles resultasen insuficientes a la hora de acallar los deseos de los españoles de libertad y democracia. El equipo y la preparación de que se les dota no les hace aptos, según se deduce de sus palabras, para la actuación frente al pueblo en defensa de la Patria, su auténtica misión. Querían dejar claro que no se les puede tratar de jóvenes egoistas e impatriotas, y que sus reivindicaciones no son injustas; todo lo contrario: «por nuestra Patria y por nuestro pueblo siempre estaremos dispuestos a derramar hasta la última gota de nuestra sangre. Siempre, no sólo durante 18 meses. Pero no por ellos, por quienes se enriquecen a costa del trabajo de todo el pueblo, ni por quienes venden trozos de la Patria a un Ejército extranjero" 30.

En cualquier caso estos soldados concienciados con la urgencia de sustituir un tipo de sociedad por otra no quisieron acabar su alegato de forma negativa. La muerte de Franco suponia el final de unas instituciones y unas leyes fascistas. Todo el conjunto de lo que se puede considerar el movimiento ciudadano, a saber, los partidos políticos, el movimiento obrero, las organizaciones populares y profesionales... amén de los militares van a salir a la luz pública y a expresar su rechazo al continuismo de

30 «Boletín informativo para oficiales y suboficiales", Una colaboración de los soldados: «Es posible disminuir el Servicio Militar»; julio, 1971 (pág. 6). 
este tipo de gobierno. Ahora ya se puede luchar juntos por la democracia aunando fuerzas y despejando la instalación del fantasma del fascismo, de nuevo, en el seno del Ejército. Ahora resta liberarlo de residuos franquistas. Por este motivo la posición que adopte las Fuerzas Armadas resultará crucial. Es necesario aumentar el esfuerzo para que éstas, con sus mandos y sus soldados, no vuelvan a ser considerados el último recurso de un gobierno para imponer sus decisiones. Es en esta tarea donde, nos dicen, los soldados, que son los hijos del pueblo, tienen probablemente que desempeñar el papel más importante. Su negativa a volver a enfrentarse con los ciudadanos, con la sociedad de la que forman parte, es la mayor garantía de un tránsito pacífico a la democracia.

Para poder cumplir con esta trascendental tarea hicieron un llamamiento a todos los soldados en general para integrar un amplio movimiento en el que, sin discriminación alguna, todos tengan cabida y todas y cada una de sus reivindicaciones sean escuchadas en su justa medida. El organizarse es una necesidad, y ésta quedará plasmada en una especie de Programa del Soldado, cuyos puntos conforman la esencia de toda su liza que, repiten, a partir de ahora seguirá por otros derroteros: El luchar por un trato digno y humano por parte de sus superiores; Una mejor alimentación y no una comida propia de cerdos; Un aumento de la paga de soldados para no ser una carga económica para las familias; Pelear por la anulación de la ley que obliga a los compañeros que se incorporan en enero a hacer el Servicio Militar fuera de su región de origen ${ }^{31}$, Luchar para que el período militar no sea un tiempo perdido en nuestras vidas sino que sirva para formarnos no sólo militarmente, sino personal y culturalmente; Lidiar por la concesión de permisos extraordinarios a los jóvenes campesinos en las épocas de mayor faena en el campo y a los estudiantes en período de exámenes. Eliminar los precios abusivos en las cantinas; Que el Hogar del soldado se convierta de verdad en un centro cultural y recreativo; $Y$, por último, que el disfrute de los permisos se haga de forma justa poniéndose fin a los enchufados.

Con estas intenciones como fondo surgió una agrupación de soldados bautizada con el nombre de Unión Democrática de Soldados cuyo fin era, precisamente, el reconocimiento a los mismos de sus derechos y libertades democráticas. La primera de estas uniones surgió en Madrid, y posteriormente se extendió al resto de España. En las diferentes regiones

31 Decreto 12 de septiembre de 1975 de reorganización del Servicio Militar, que establece desde el 1 de enero de 1976 se cumplirá el Servicio Militar fuera de la región de origen donde haya sido alistado el recluta. 
tendría la misma denominación excepto en Galicia, donde se la conocerá como Unión de Soldados Demócratas, ya que, según sus explicaciones, creían que así se expresaba mejor el carácter y las metas que se planteaban: conseguir la democracia. En la nueva España surgida tras 1975 cuentan con la ventaja de poder celebrar congresos regionales y nacionales 32 así como de todo el Estado e, incluso, federarse.

A pesar de que hubo otras reuniones y sus actuaciones comenzaron a concretarse antes ${ }^{33}$, el 1 de abril de 1978 la Comisión Ejecutiva Federal celebró su tercera reunión plenaria, la cual es muy importante destacar porque, según sus propios miembros es una fecha histórica para el Movimiento de Soldados en nuestro pais, porque sirvió para demostrar su decisión de seguir infatigables en el combate por solucionar sus problemas, amén de su deseo de diálogo evitando todo tipo de enfrentamiento con los mandos y evitando asimismo el romper la disciplina.

Tras la reunión se aprobó un plan de trabajo inmediato que contenía los siguientes puntos: La realización de una campaña permanente de propaganda sobre su programa mínimo; Un plan de saneamiento económico; Pasar a organizar la afiliación masiva de los soldados en las Uniones; $Y$ dedicar su esfuerzo sobre todo al desarrollo del trabajo sindical en los cuarteles.

Sus deseos y reivindicaciones serían compartidos por otras fuerzas análogas a elios en su forma de pensar y de actuar -a saber, las Juven-

32 En octubre del año 1977 tuvo lugar una reunión de la Comisión Ejecutiva de la UDS con los portavoces de las distintas Uniones nacionales y regionales. El objeto de la reunión fue proponer un programa y unos Estatutos que habrían de ser discutidos por los miembros de todas las Uniones. Se acordó avanzar en todas las Uniones hacia sus Congresos respectivos así como hacia el Congreso Estatal en donde se apruebe el nuevo programa y el nuevo Estatuto de la Federación.

Para la celebración de los congresos nacionales y regionales se plantearon dar unos pasos concretos: Consolidar las Uniones en cada cuartel y constituirlas allí donde no existan; Promover Asambleas de Delegados de Cuartel en cada zona y localidad; Y, por último, elegir en estas Asambleas a una Comisión Ejecutiva Provisional que será la encargada de preparar el Congreso.

Además de todo esto también se acordó apoyar decididamente la campaña por la Amnistía Militar, que recordemos se estaba llevando a cabo en estos momentos por todo el país, y distribuir el carnet de la Federación entre todos sus miembros, ya que consideraron que esto permitiría un mejor funcionamiento de la organización que, según sus propias estadísticas, contaba con miles de miembros.

33 Al igual que sucediera con los oficiales de la UMD hubo soldados retenidos en calabozos acusados de su pertenencia a la UDS y de llevar a cabo actividades sospechosas relacionadas con esta organización. A los detenidos se les abrió procesc por sedición, siendo no obstante ya varios a los que se les habia retirado este proceso, sustituyéndolo por faltas graves con arresto de 2 a 6 meses. 
tudes Socialistas (JJ.SS.), la Joven Guardia Roja de España (JGRE), las Juventudes de Izquierda Democrática (JID) y el ala radical del Partido Liberal (ARPL)-, lo que les llevará a la elaboración de una Declaración conjunta que transformarán en un Manifiesto del Soldado, que sirva para regular el ejercicio de los derechos constitucionales para los militares dentro de los cuarteles. Sus peticiones son: Primero.- Que la Constitución reconozca a los soldados todos los derechos y libertades políticas y civiles, y que los soldados, fuera del cuartel y sin uniforme, sean sujetos de los mismos derechos y deberes que el resto de los ciudadanos. Segundo.- Que todos los ciudadanos tengan reconocido el derecho a la objeción de conciencia por motivos políticos, religiosos o filosóficos, pudiendo optar por la prestación de un servicio civil. Tercero.- Que se elabore una nueva ley de Servicio Militar Obligatorio que garantice y regule el ejercicio de los derechos constitucionales en los cuarteles. Esta Ley debería recoger los siguientes derechos: a) La libertad de conciencia, pensamiento y religión y el cese de la obligatoriedad a asistir a actos religiosos de cualquier confesionalidad en los cuarteles; b) La libertad de expresión, pudiendo los soldados manifestar libremente sus opiniones, oralmente o por escrito, sin tener que someterse a ningún tipo de censura, con la única limitación de los asuntos referentes a los secretos de la Defensa Nacional; c) El derecho de asociación para poder crear libremente entidades de tipo cultural, deportivo o recreativo, o para la mejora de todos los aspectos de la vida del cuartel, así como para impulsar actividades que supongan el aumento del bienestar general de la tropa; d) El derecho de representación. Deberá permitirse la formación de comisiones de representantes o de portavoces elegidos por los soldados para transmitir al mando las quejas o los motivos de insatisfacción, así como las sugerencias o propuestas para mejorar las condiciones de vida y de servicio en los cuarteles. Cuarto.- Deberá ser reformado el Código de Justicia Militar, aboliéndose la Ley de Jurisdicciones y el aforamiento por razón de la persona o el lugar, quedando reducida la Justicia Militar a las faltas y delitos estrictamente militares. $Y$ quinto.- Deberá establecerse en cada cuartel un Tribunal de Apelación del que formen parte todas las clases del Ejército, ante el cual puedan interponer recurso los soldados sancionados a título de falta. Este tribunal también tendrá funciones de control sobre las condiciones de vida de los cuarteles.

Madrid, a 17 de octubre de $1977^{34}$

34 Fuente: "La voz de los cuarteles»; Portavoz de la Federación de Uniones de Soldados y Marineros Demócratas de las Fuerzas Armadas. 
En suma, y como se ha podido apreciar, no todo el conjunto de las Fuerzas Armadas permaneció impasible ante los cambios tan trascendentales que se estaban experimentado en la sociedad española del último cuarto del siglo XX. Hubo un grupo entre los oficiales y los soldados que se atrevieron a desafiar las normas, impulsados por sus propias necesidades y ante la oportunidad que para ellos suponía el subirse al carro de la democracia. En el futuro inmediato se vislumbraba un importante reto para ellos, aunque sólo fuese por el hecho de que, a su parecer, la historia les brindaba la oportunidad de renovar las estructuras establecidas. Por eso el mérito, si es que cabe atribuir mérito alguno, consistió en haberse arriesgado a identificarse con la nueva situación, aportando un argumento más a favor de ese ya tan repetido cambio que estaba fraguándose. A partir de ahora, y al constituirse en la avanzadilla de la causa por la libertad, debieron superar los problemas propios de su adaptación y emprender la ingente misión de colocar al colectivo militar en el puesto que le correspondía en una nueva sociedad demócrata.

\section{BIBLIOGRAFÍA}

Fuentes primarias

Propaganda clandestina

Andalucía militar

Boletín informativo para oficiales y suboficiales

Misión

Nueva lealtad

La voz de los cuarteles

La voz del soldado

Unión militar democrática

Documentos

Ideario

El rnanifiesto

El estatuto del militar ¿dónde están los capitanes?

La UMD y la causa 250/75

Declaraciones y comunicados

Exposición política tras la muerte de Franco (1975)

Por la libertad hacia la justicia social

Comunicado a todos los españoles

La U.M.D. ante la nueva situación política

Información sobre lo que es la U.M.D. 
Fuentes secundarias

Aguilar Olivencia, M.: El Ejército español durante el franquismo Madrid, Akal, 1999.

Busouets Bragulat, J.: El militar de carrera en España Barcelona, Ariel, 1967. Busquets Bragulat, J.: Militares y Demócratas Barcelona, Plaza y Janés, 1999. COLOMER, J.: La transición a la democracia el modelo español Barcelona, Anagrama, 1988.

Falange Española y Tradicionalista De Las Jons.: Palabras del Caudillo ediciones FE, 1939.

FERNÁNDEZ LÓPEZ, J.: Los militares en el cambio político en España (1969/1982) (sin editar). 